\title{
A new wireless ultrasound probe for ultrasound guided central venous access
}

\author{
M Pittiruti ${ }^{1 *}$, A Emoli², S Cappuccio², A La Greca' \\ From 7th WINFOCUS Italian Congress on Ultrasound in Emergency, Anaesthesiology and Critical Care \\ Lodi, Italy. 26-29 March 2014
}

\section{Background}

Ultrasound (US) is considered mandatory for placement of central venous access devices (VAD), both for venepuncture and for early detection of potential complications.

\section{Objective}

We report our preliminary experience with a new US device equipped with a wireless linear transducer (Acuson Freestyle, Siemens), specifically made for US-guided procedures.

\section{Patients and methods}

The US system we tested consists of a $5-13 \mathrm{MHz}$ linear probe connected by wireless technology $(8 \mathrm{GHz}$ ultra wide band) to a compact, keyboardless device. The probe can be completely wrapped up in a sterile cover so to perform the procedure with maximal barrier precautions. The main functions (gain, depth, freeze, save, etc.) can be operated either by controls built-in in the transducer or directly on the screen of the device. We adopted this wireless systems in 38 consecutive VAD placements (25 PICCs, 12 ports and 1 cuffed-tunneled catheter). US was used for US-guided puncture and cannulation of different veins (20 basilic veins, 5 brachial veins, 9 axillary-subclavian veins, 3 internal jugular veins and 1 brachio-cephalic vein), for US detection of potential misplacement of the guidewire and/or of the catheter, as well as for ruling out pneumothorax by US scan of the pleura in the intercostal space.

\section{Results}

All venepunctures were performed successfully. The image quality was excellent and there was no delay in the data trasmission to the screen. The transducer was easy to handle and to use. Visualization of needles,

"Emergency Surgery Unit, "A. Gemelli" Hospital - Catholic University - Roma, Italy Full list of author information is available at the end of the article guidewires and catheters was optimal. All operators reported an increased easiness in performing the USguided maneuvers, due to the absence of the cable.

\section{Conclusion}

Our experience suggests that wireless US might be specifically useful in US-guided procedures. Some of its potential advantages are: maximal flexibility in placing the device and the probe, as their connection is wireless; complete freedom of movement for the operator during the procedure; optimal compliance with the current recommendations for infection control.

\section{Authors' details}

'Emergency Surgery Unit, "A. Gemelli" Hospital - Catholic University - Roma, Italy. 2Dept. of Oncology, "A. Gemelli" Hospital - Catholic University - Roma, Italy.

Published: 27 August 2014

doi:10.1186/2036-7902-6-S2-A12

Cite this article as: Pittiruti et al: A new wireless ultrasound probe for ultrasound guided central venous access. Critical Ultrasound Journal 2014 6(Suppl 2):A12.

Submit your manuscript to a SpringerOpen ${ }^{\circ}$ journal and benefit from:

- Convenient online submission

- Rigorous peer review

- Immediate publication on acceptance

- Open access: articles freely available online

- High visibility within the field

- Retaining the copyright to your article

Submit your next manuscript at $\gg$ springeropen.com
(C) 2014 Pittiruti et al; licensee Springer This is an Open Access article distributed under the terms of the Creative Commons Attribution License (http://creativecommons.org/licenses/by/2.0), which permits unrestricted use, distribution, and reproduction in any medium, provided the original work is properly cited. 